Archives de sciences sociales des religions

134 | avril - juin 2006

Varia

\title{
De la caricature anticléricale à la farce biblique
}

\section{Guillaume Doizy}

\section{OpenEdition}

Journals

Édition électronique

URL : http://journals.openedition.org/assr/3660

DOI : $10.4000 /$ assr.3660

ISSN : $1777-5825$

Éditeur

Éditions de l'EHESS

Édition imprimée

Date de publication : 1 mai 2006

Pagination : 63-91

ISBN : 2-7132-2092-0

ISSN : 0335-5985

Référence électronique

Guillaume Doizy, «De la caricature anticléricale à la farce biblique », Archives de sciences sociales des religions [En ligne], 134 | avril - juin 2006, mis en ligne le 18 octobre 2009, consulté le 10 décembre 2020. URL : http://journals.openedition.org/assr/3660 ; DOI : https://doi.org/10.4000/assr.3660 


\section{Guillaume Doizy}

\section{De la caricature anticléricale à la farce biblique}

\section{Une tradition de caricature}

La caricature anticléricale en France s'est principalement attaquée depuis son origine aux membres du clergé catholique. Le terme «anticlérical», dans son acception première, s'oppose à «clérical ", c'est-à-dire à l'influence temporelle (politique, sociale, morale) de l'Église et de ses membres sur la société ${ }^{1}$. Et en effet, la production d'images hostiles à l'Église depuis la Réforme jusqu'à aujourd'hui, fourmille de curés gourmands, lubriques ou «pédophiles », de moines réactionnaires et monarchistes, paresseux et cupides, de prélats, d'évêques, de cardinaux, voire de papes ridiculisés, déformés, animalisés pour mieux démontrer leur nuisance sur la société. L'anticléricalisme de la caricature est bien connu.

Mais le mouvement hostile à l'Église se serait-il contenté de ce seul registre? La caricature n'aurait-elle donc jamais visé la Bible, Ancien et Nouveau Testament, voire d'autres textes et figures "sacrés » des religions dites du Livre? Il faut en fait attendre les années 1880 et la forte poussée républicaine, laïciste et libre penseuse pour voir la caricature fondre sur les textes «saints". Il se publie alors de véritables parodies des Écritures dont la caractéristique principale est de comporter des illustrations satiriques ${ }^{2}$. La presse anticléricale la plus radicale n'hésite pas, elle non plus, à s'en prendre à l'Ancien et au Nouveau Testament. Comment comprendre cet accès antichrétien qui semble se concentrer dans la période $1880-1914^{3}$ ?

Dès les premiers temps du christianisme se multiplient les attaques contre la Bible ou la religion des chrétiens, sous forme littéraire, dessinée ou théâtrale, souvent sarcastique, voire satirique. Certains juifs dénoncent l'idolâtrie et l'immoralité des chrétiens. Tertullien, un défenseur du christianisme se plaint du fait

1. René Rémond, L'anticléricalisme en France de 1815 à nos jours, Paris, Fayard, 1999, p. 10.

2. Jacqueline Lalouette, La Libre pensée en France, 1848-1940, Paris, Albin Michel, 2001, p. 205 sq. ainsi que « iconoclastie et caricature dans le combat libre-penseur et anticlérical (1879-1894) » in Stéphane Michaud, Jean-Yves Moldier, Nicole SaVY, dirs, Usages de l'image au XIX ${ }^{e}$ siècle, Paris Créaphis, 1992, p. 51-61.

3. Le propagandiste André LORULOT publiera dans les années 1930 une Bible comique et une Vie de Jésus illustrées largement inspirées des productions d'avant 1914. 
$q u$ ' « on vient de faire paraître (...) une nouvelle figure de notre Dieu ». Il s'agirait d'une «peinture avec l'inscription suivante : LE DIEU-ÂNE DES CHRÉTIENS ; il avait des oreilles d'âne et un pied en sabot, tenait un livre à la main et était vêtu d'une toge ${ }^{4}$. Et en effet, un graffiti antique retrouvé à Rome ${ }^{5}$, datant des premiers temps du christianisme, représente un personnage crucifié muni d'une tête d'âne et devant lequel s'affaire un croyant avec cette inscription : "Alexamène adore Dieu » [fig. 1].

Les païens raillent la Bible. Celse par exemple, dans son Discours véritable composé au II siècle, voit dans la Genèse une «fable " pour «âmes viles et imbéciles ". Pour lui, cette religion s'adresse aux ignorants. Au siècle suivant, Porphyre rit à l'idée que "le divin soit descendu dans le sein de la vierge Marie, qu’il soit devenu embryon, qu'après sa naissance il ait été enveloppé de langes, tout sali de sang, de bile et pis encore ». Les paiens organisent des représentations théâtrales satiriques contre la communion et la messe ${ }^{6}$. Mais la nouvelle religion se montre de plus en plus agressive. Au Moyen Âge, l'Inquisition impose la terreur et l'expression de tout doute à l'égard des Écritures devient difficile, voire impossible pendant de longs siècles.

Les philosophes anticléricaux du XVIII ${ }^{\mathrm{e}}$ siècle en France, concentrent leurs critiques contre l'Église catholique et ses abus de pouvoir, son refus de la science et des progrès de la pensée, son rôle oppresseur. Voltaire, qui aura une très forte influence sur les générations anticléricales qui suivront, et notamment les satiristes, s’intéresse à la Bible. Dans son Dictionnaire philosophique, il accable la religion. Un long paragraphe sur la Genèse la qualifie de « fable aussi exécrable qu'absurde ». Voltaire use d'un ton particulièrement insolent et ironique. Mais comme l'indique l'historien René Pomeau, le philosophe veut certes «abolir les croyances millénaires sur lesquelles se fondait la civilisation de l'Europe » ${ }^{7}$, mais pour les remplacer par une croyance naturelle, sans textes soi-disant révélés à adorer. Il est anti-chrétien, et, par là même, refuse ce que les catholiques ont fait de leur divinité. Voltaire abhorre l'Église dont il combat l'obscurantisme et la violence. Mais, en déiste, il attaque l'athéisme d'Holbach ou de Diderot par exemple.

Même la Révolution française, malgré ses mesures radicales contre l’Église catholique, restera déiste, et voudra remplacer le christianisme par le culte de l'Être suprême associé à celui de l'immortalité de l'âme. Mais cette période marque une profonde rupture dans le rapport au dogme, et ce, malgré les différentes Restaurations qui vont suivre. Tout au long du XIX ${ }^{\mathrm{e}}$ siècle se met en place une critique du christianisme qui emprunte deux chemins, parfois convergents.

4. Cité par Chamfleury dans Histoire de la caricature antique, 1867, p. 292.

5. Reproduit par Ernst KRIS, Psychanalyse de l'Art, Le fil rouge, Paris, PUF, 1978.

6. Ray Macmullen, Christianisme et paganisme du IV au VIII siècle, Les Belles-Lettres, coll. " Histoire ", p. 35-43.

7. René POMEAU, Voltaire en son temps, Paris, Fayard/Voltaire Foundation, 1995, t. 2, p. 4. 


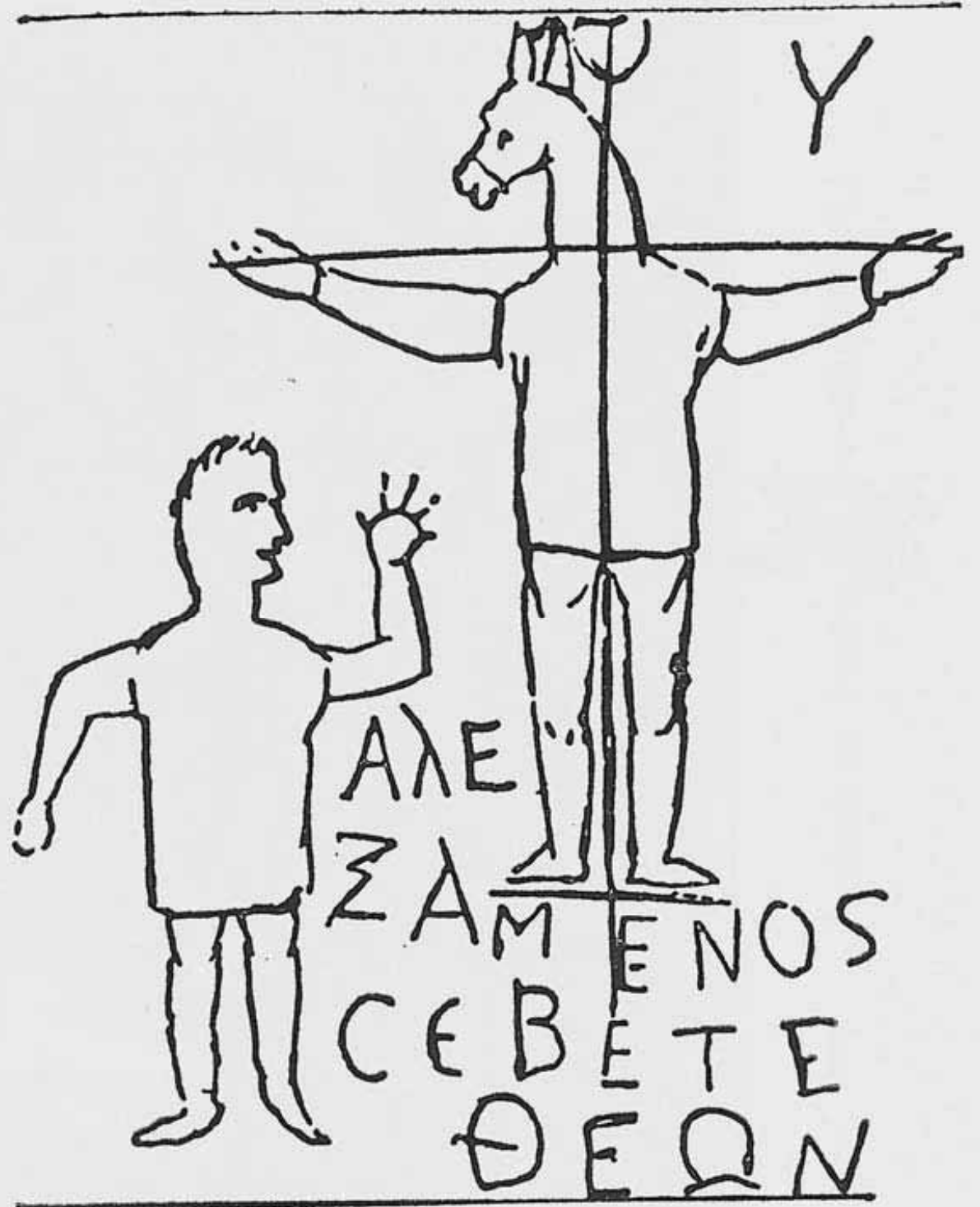

Fig. 1

D'un côté une critique rationnelle ${ }^{8}$ des textes s'appuie sur les découvertes scientifiques, s'intéresse à l'historiographie ancienne et aux contradictions des textes « saints". On pense évidemment à Renan par exemple et à sa célèbre Vie de Jésus. De l'autre se multiplient les assauts satiriques qui trouvent dans le comique un fort bon moyen de dénigrement. La critique sérieuse vise les élites; le rire, de son côté, tend à transcrire les arguments en termes accessibles pour le plus grand nombre.

Il faut attendre la Commune de Paris pour rencontrer les premières images satiriques contre Dieu. Néanmoins, suite aux bouleversements idéologiques et

8. Georges WEIL, Histoire de l'idée lä̈que en France au XIX ${ }^{e}$ siècle, Paris, Hachette Littérature, $2004(1929)$. 
culturels générés par la Révolution française, la caricature républicaine, tout au long du XIX siècle, se réfère parfois à des scènes fameuses de la Bible pour attaquer ses adversaires politiques. Traviès, en 1834, dans une gravure intitulée «Le Festin de Balthazar ${ }^{9}$ attaque Louis Philippe dont le dossier de chaise est transformé en poire. Reprenant une légende tirée du livre de Daniel, le dessinateur présente un festin mouvementé lors duquel une main mystérieuse écrit (normalement sur un mur) à même un nuage, "Ca n'durera pas toujours ", reflétant l'espoir des républicains de voir changer le régime [fig. 2]. Dans les périodes où la censure se relâche, les métaphores bibliques se multiplient. Sous la plume de Gill, en 1871, Ève se voit tentée par un serpent orléaniste. Une charge de Pasquin [fig. 3] dans le journal le Titi, montre Gambetta et la République dénudés, à côté d'un bel arbre autour duquel est enroulé un serpent à tête de jésuite. Comme l'indique le titre, il s'agit d'une transposition de «Adam et Ėve au paradis terrestre ». L'Adam républicain croque la pomme, alors qu'Ève-Marianne s'en détourne ${ }^{10}$.

Plus tard, en 1899, en pleine affaire Dreyfus, le dessinateur Pépin convoque Dieu lui-même en couverture du Grelot. Présenté sur un nuage ou une simple planche à roulette, il est censé protéger la France ou trancher la question de la Révision. On pourrait multiplier les exemples. Notons que ces images ne visent pas vraiment à ridiculiser le dogme. Elles fonctionnent comme n'importe quelle autre métaphore. Néanmoins, sous couvert de caricatures politiques visant les régimes contemporains des dessinateurs, le recours à la Bible comme source d'inspiration traduit une baisse du respect social à l'égard des textes "sacrés". Le détournement des Écritures, qui depuis la période révolutionnaire subissent une forme de laïcisation progressive (par le truchement du regard historiographique notamment), n'est plus considéré comme sacrilège, bien que leur critique directe reste encore vécue comme blasphématoire. L'émancipation vis-à-vis du sacré prend, tout au long du XIX ${ }^{e}$ siècle, des chemins sinueux.

\section{Républicains et libres penseurs}

Les premières charges contre Dieu sont éditées pendant la «sacrilège » Commune de Paris, qui rappelons-le, a décrété la séparation des Églises et de l'État, seconde du genre après celle de la Révolution française. Comme l'indique E. Money en 1872, les caricaturistes, non contents d'attaquer le clergé, ont "même porté leur audace ", dans une série intitulé "La Calotte ", jusqu’à représenter "le "Père éternel" sous les traits d'un vieux philosophe, le nez chaussé de lunettes, la barbe jaunie par l'usage du tabac et de la bière, les poches bourrées

9. TraviÈs, «Le Festin de Balthazar », La Caricature, no 181, 1834.

10. PASQUIN, "Adam et Ève dans le paradis terrestre ", Le Titi, 21 novembre 1879. 


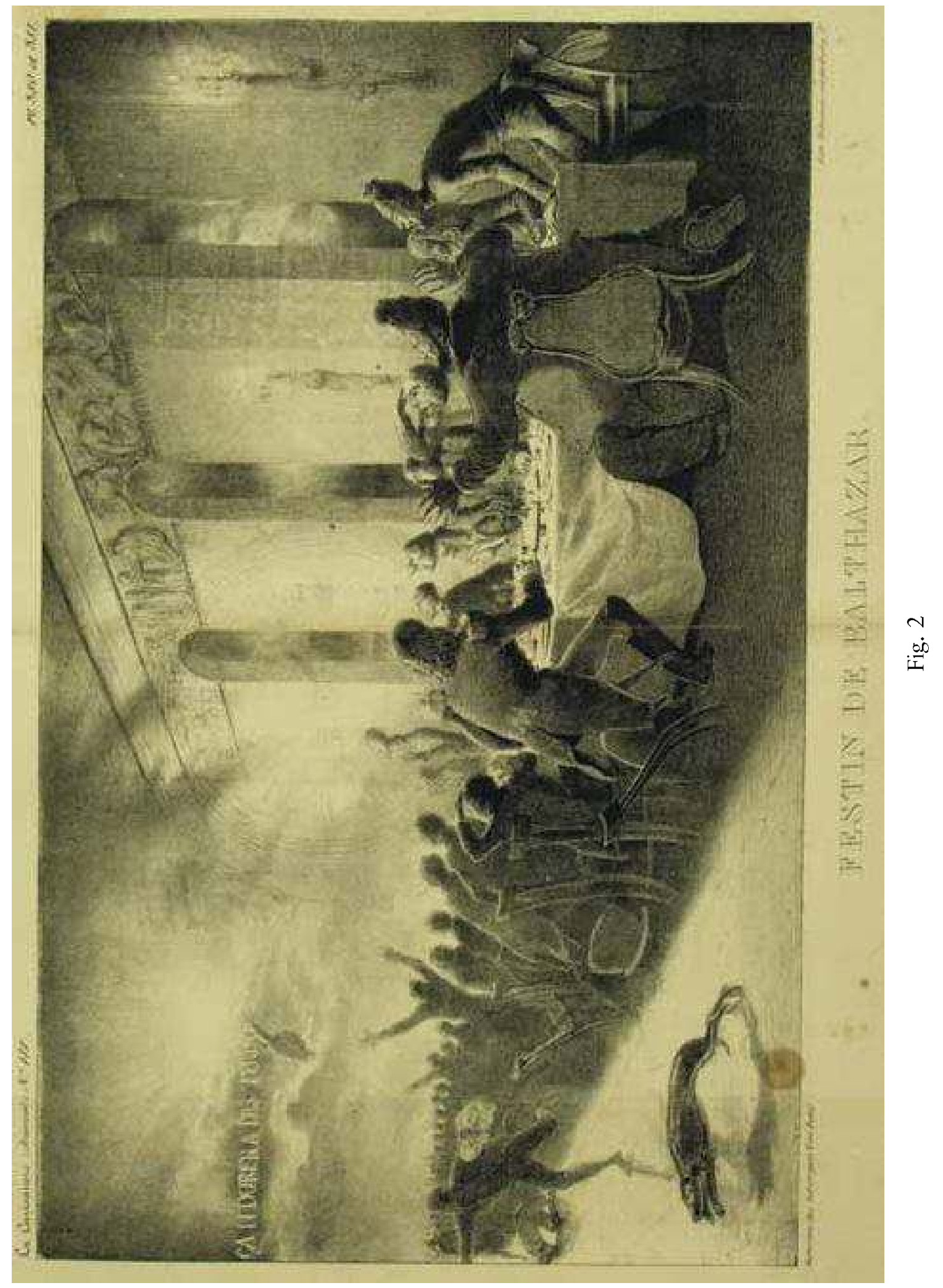




\section{T TTग ADUII ET GWEDAISLE PURIDIS TERRESTRE 5. Si vous voulex savoir pourqquoi notro ami mange in pomme, is CHAUFFEZ entro ua promiso of liti et lo paradin parlera.

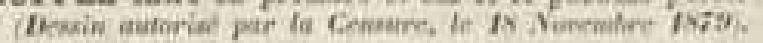

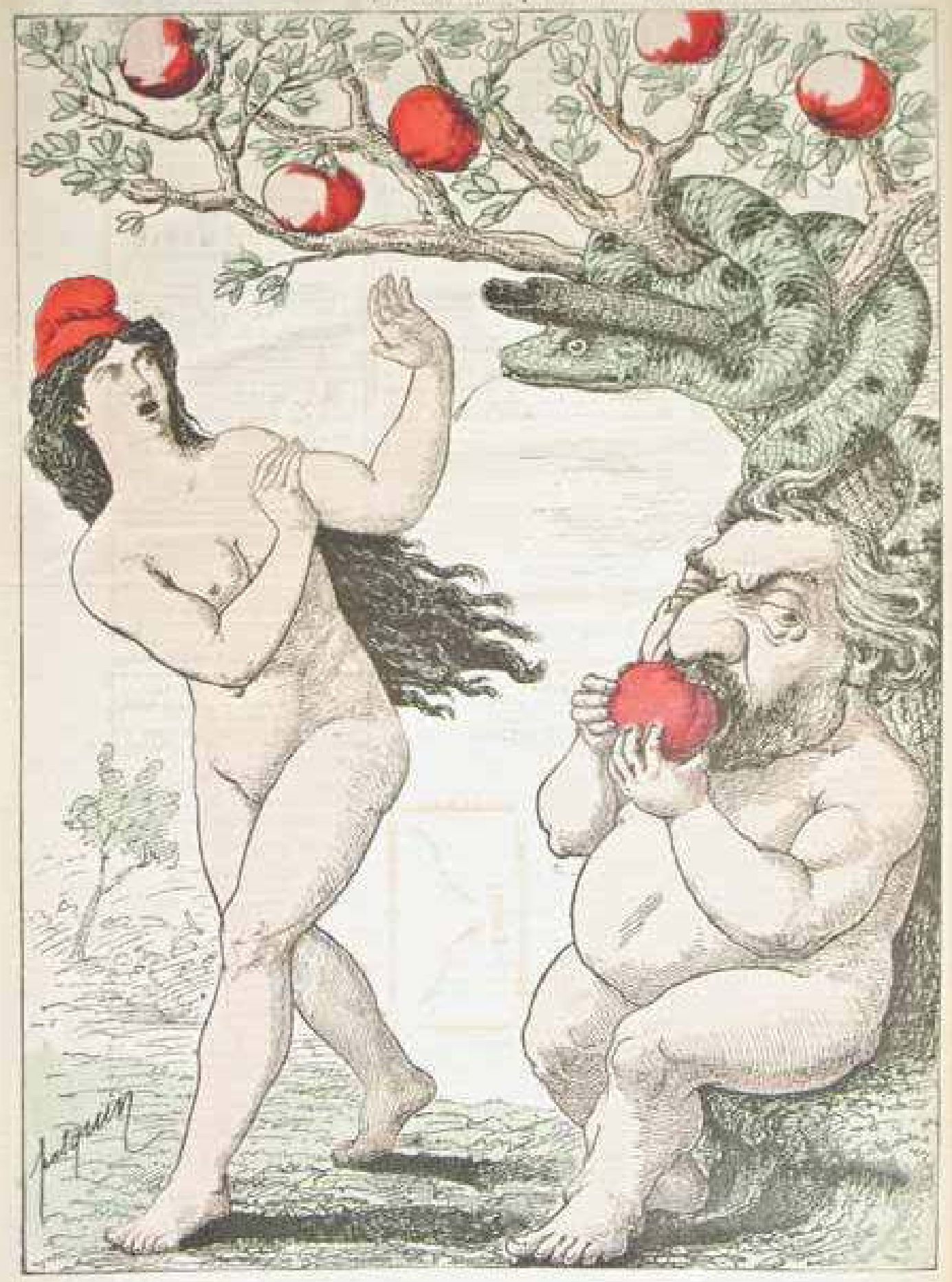

Fig. 3 
d'obligations et d'actions de chemin de fer ${ }^{11}$ [fig. 4]. L'auteur de ce dessin n'est autre que Klenck, un des caricaturistes les plus prolixes de la Commune puisqu'il aurait à lui seul signé plus de 210 planches différentes. Pillotel n'est pas en reste, puisque, ancien membre de la Commune, en exil en Angleterre, il fait paraître une série de gravures, pour certaines datées de 1870 ou 1871, dans lesquelles il salue l'athéisme révolutionnaire, s'en prend au «Dieu pétroleur » à propos de l'incendie de Sodome, et dans un dessin présentant des statuettes de différents dieux s'écrie : "décidément, si Dieu existait, il faudrait l'exécuter » [fig. 5].

Ces caricatures restent alors isolées, mais, par leur ton trivial et comique, elle annoncent les nombreuses saillies de l'imagerie satirique contre les Écritures des années 1880. Plusieurs facteurs favorables se dessinent alors. On assiste dans la seconde moitié du XIX siècle d'une part à un extraordinaire développement des moyens d'impression de l'image. D'autre part, à la fin des années 1870 s'impose un mouvement libre penseur dynamique et militant, qui professe un athéisme de plus en plus radical. Enfin, la loi de juillet 1881 sur la presse donne toute liberté (ou presque) au dessinateur et abandonne le délit d'atteinte à la morale religieuse. Le vote de la loi sanctionne en fait une liberté acquise en partie depuis quelques mois.

On doit la première tentative de Bible irrévérencieuse accompagnée d'images satiriques à l'écrivain et journaliste républicain franc-maçon Pierre Malvezin. Sous le gouvernement de Mac-Mahon, Malvezin avait déjà publié, sans qu'elle soit encore illustrée, sa Bible farce ou Bible comme elle est ${ }^{12}$, présentée comme une "parodie des livres sacrés». En 1880, le dessinateur Alfred Le Petit qui donne alors dans un anticléricalisme virulent et joyeux illustre l'ouvrage d'une cinquantaine de dessins au trait dont certains sont en couleur [fig. 6]. De son côté, Léo Taxil, fondateur de nombreux journaux satiriques et de deux journaux politiques militants illustrés de caricatures, reprend l'idée et publie entre autres une Bible amusante pour les grands et petits enfants ${ }^{13}$ décrite comme "restant dans les limites de la plus scrupuleuse morale » alors qu'aucun auteur jusque-là n'aurait "poussé aussi loin le rire et la moquerie à l'égard des individus soidisant saints et des choses prétendues sacrées ${ }^{14}$. L'ouvrage est réédité sous le titre de Bible folichonne ${ }^{15}$ puis réécrit avec un texte plus abondant en 1898 , version qui sera de nouveau rééditée. Toutes sont illustrées de dessins de Frid'Rick.

11. E. MoneY, « La caricature sous la Commune », Revue de France, avril-juin 1872, p. 42.

12. Pierre MaLveZIn, La Bible Farce ou la Bible comme elle est. Traduction nouvelle des livres comico-sacrés avec texte à l'appui, édition illustrée par Alfred Le Petit, Paris, chez l'auteur, s.d. (1881).

13. Léo TAXII, La Bible amusante pour les grands et les petits enfants (dessins par Frid'rick, diffusée à partir de mars 1881 en livraisons), éditée reliée en 1882, et rééditée en 1897-1898 puis en 1901.

14. L'Anti-clérical, 9 mars 1881.

15. LEO-TARD, La Bible folichonne et autres farces dédiées aux rieurs (illustrations de Frid'Rick), Paris, B. Simon, s.d. (1887). 
70 - ARCHIVES DE SCIENCES SOCIALES DES RELIGIONS

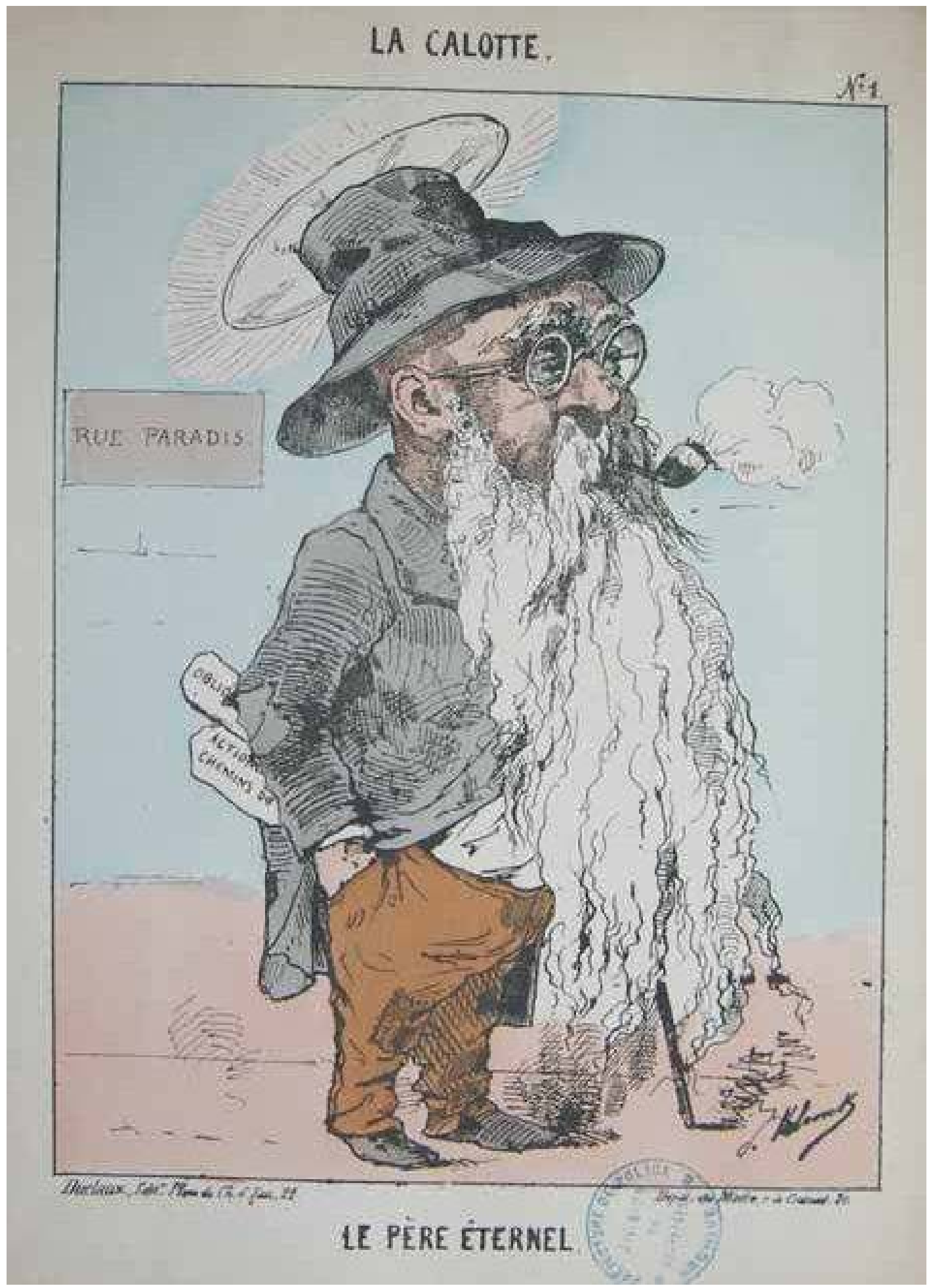

Fig. 4 


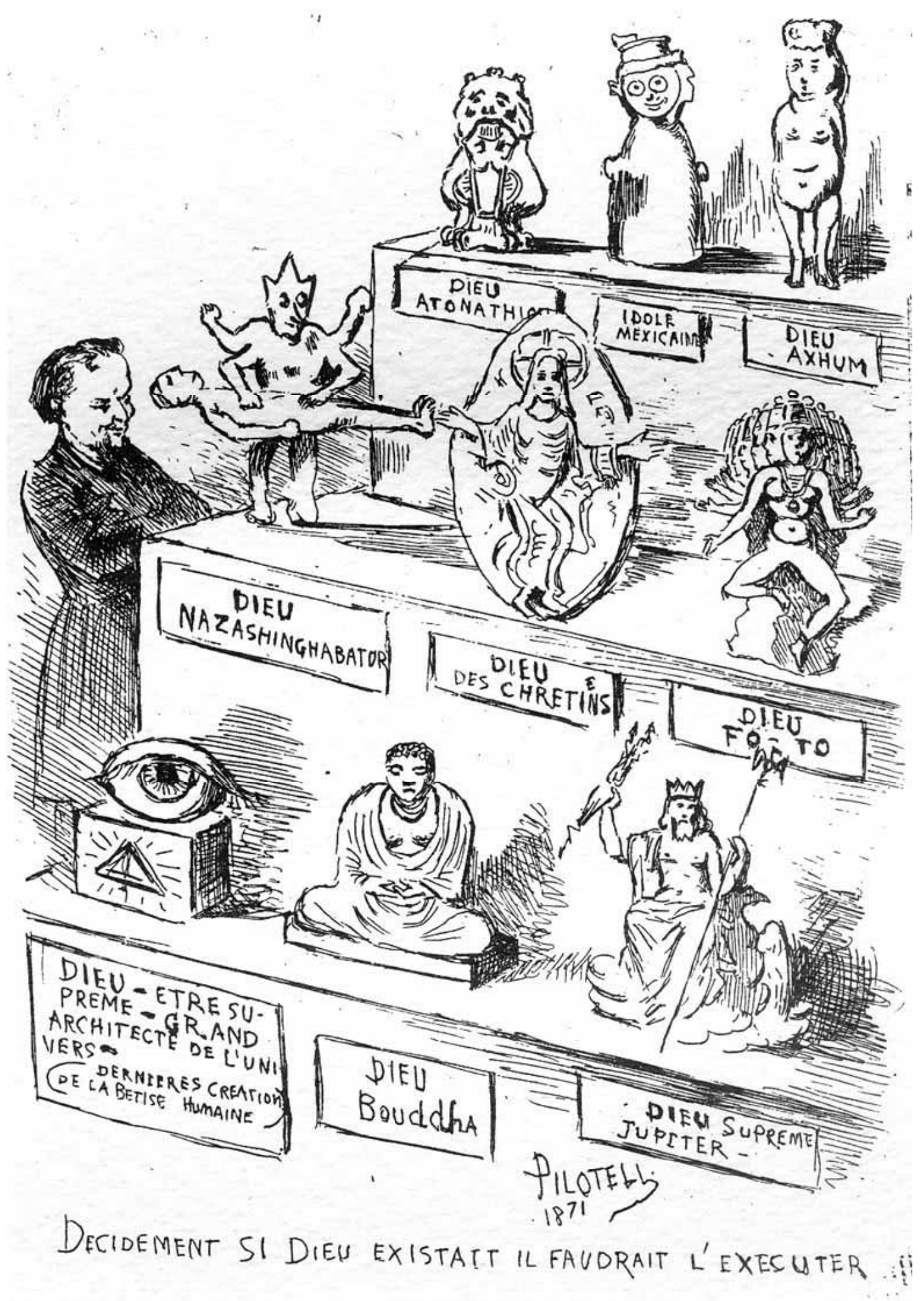

Fig. 5 


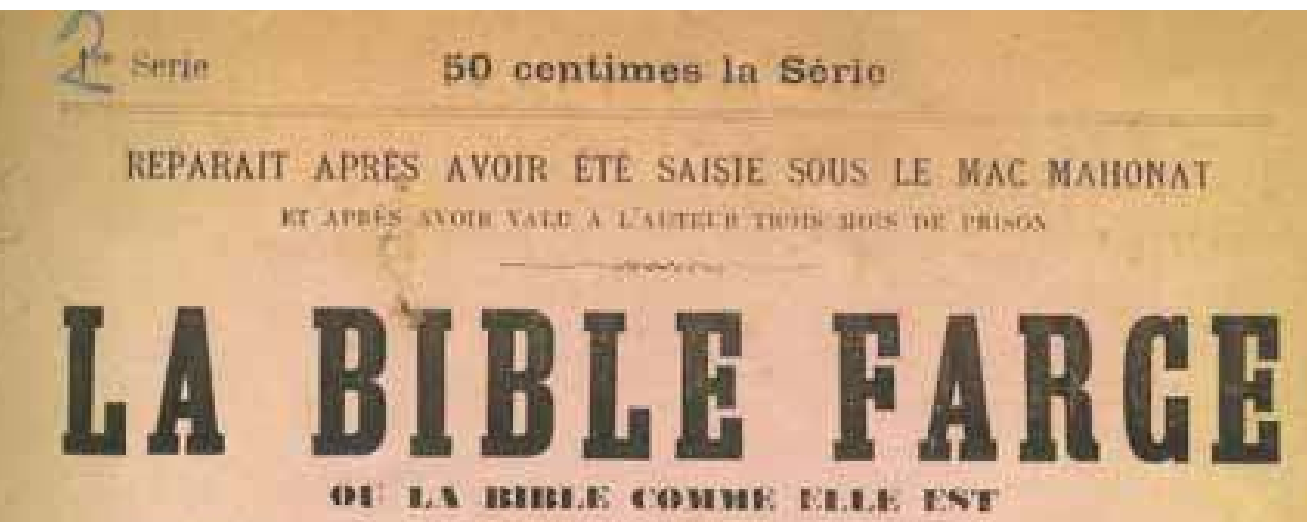

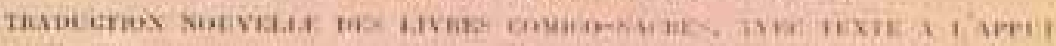

\section{PAR PIERRE MALVEZIK}

HLLUSTREE PAR ALFRED LE WHTT

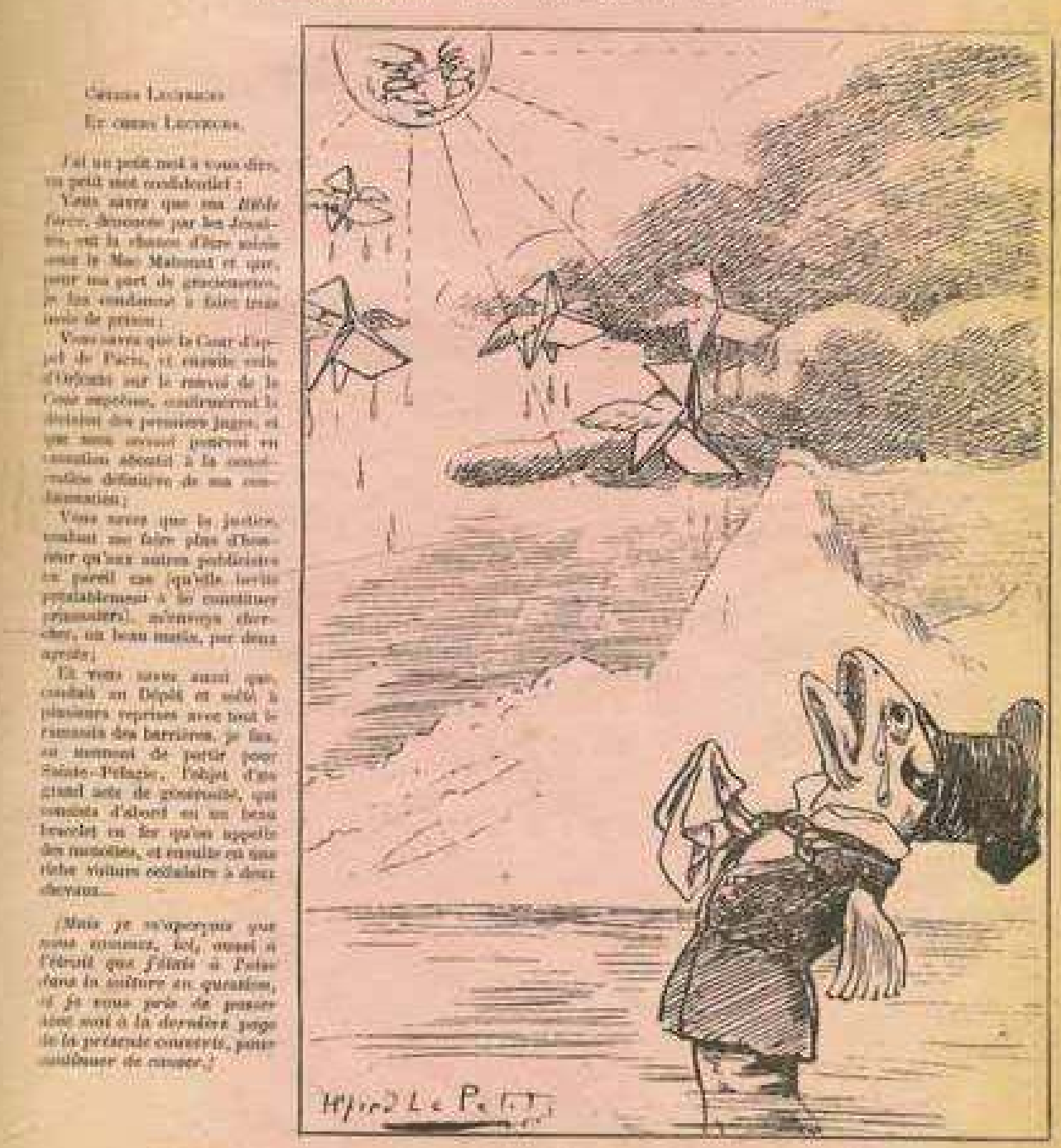

Paris, chez tous les Iibraires

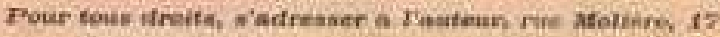

Fig. 6 
Taxil n'est pas un simple littérateur, mais un militant. Il crée une Ligue anticléricale, particulièrement dynamique comportant bientôt des dizaines de groupes et quelques milliers d'adhérents. Il s'adresse à de nombreux dessinateurs pour illustrer les organes de presse de tendance anticléricale qu'il dirige, l'Anti-clérical et la République anti-cléricale notamment. On lui doit de nombreux ouvrages où se mêlent polémique, satire et journalisme, ayant le plus souvent pour seule cible l'Église catholique voire ses dogmes comme la Trinité par exemple. Ce polémiste est même présenté, au moment où il se retire du mouvement anticlérical, en 1885, comme "l'auteur de la Bible Amusante qui a si bien saisi et fustigé les imbécillités et les saloperies des livres saints ${ }^{16}$. Au travers de ces Bibles satiriques, il vise à faire, comme il l'écrit lui-même, œuvre de "propagande ».

Le genre s'impose. Le dessinateur Lavrate (principal dessinateur du Monde plaisant, de tendance républicaine) publie en 1881 en fascicules (pour un public populaire, donc) une Bible pour rire ${ }^{17}$ composée au final de 306 dessins. Un peu plus tard, Auguste Deslinières, sous le pseudonyme de Beausapin est à son tour l'auteur d'une satire de plusieurs centaines de pages contre l'Ancien Testament qu'il intitule Bible comique ${ }^{18}$, et qui reprend certains dessins de Lavrate. Ces textes donnent une vision drolatique des textes saints.

La presse diffuse dans ses colonnes des écrits de la même veine, comme cette «Bible de Méphisto ${ }^{19}$ en vers, signée Émile Goudeau, mais non illustrée, publiée par le journal militant La Libre Pensée. Au début des années 1890 l'engouement athéiste perdure, avec une nouvelle Sainte Bible racontée par un Auvergnat ${ }^{20}$, que le lecteur peut déguster en feuilleton dans le journal La France Anti-cléricale, ou sous la forme d'un livre relié, illustré par le dessinateur et satiriste Moynet.

Les Évangiles font l'objet d'un égal intérêt dans les années 1880. Léo Taxil épaulé par le célèbre dessinateur Pépin (un des principaux dessinateurs du Grelot), républicain anticlérical convaincu, rédige une importante Vie de Jésus ${ }^{21}$, où alternent des dessins pleine page et d'autres, sans cadre, intégrés au texte [fig. 7]. L'ouvrage bénéficiera de plusieurs rééditions. Une autre satire paraît durant cette période et s'attaque tout autant à l'Ancien qu'au Nouveau Testament. Réimprimé des dizaines de fois pendant les décennies précédentes, Gros-Jean et son curé ${ }^{22}$, de Roussel de Méry, se présente comme un dialogue entre un philosophe sceptique

16. La République anti-cléricale, $\mathrm{n}^{\circ} 339,5$ août 1885.

17. LaVRate. La Bible pour Rire, Paris, Librairie du monde plaisant, 1881.

18. Auguste Deslinières Beausapin, Bible comique (dessins de Lavrate), Paris, Librairie Comique, s.d. (vendue en livraisons à partir d'octobre 1883).

19. La Libre Pensée, "Journal anti-religieux hebdomadaire" du 11 et du 18 juillet 1881.

20. Anonyme, La Sainte Bible racontée par un Auvergnat (dessins de G. Moynet), Paris, Librairie des publications modernes, 1892.

21. Léo TAXIL, La Vie de Jésus, "Dessins comiques par Pépin ", Librairie anti-cléricale, 1884, puis réédition en 1900 .

22. Auguste Roussel, De Mery, Gros-Jean et son curé, « illustré d'environ 200 magnifiques dessins d'Alfred Le Petit ", 1881 et, réédité en 1905. 


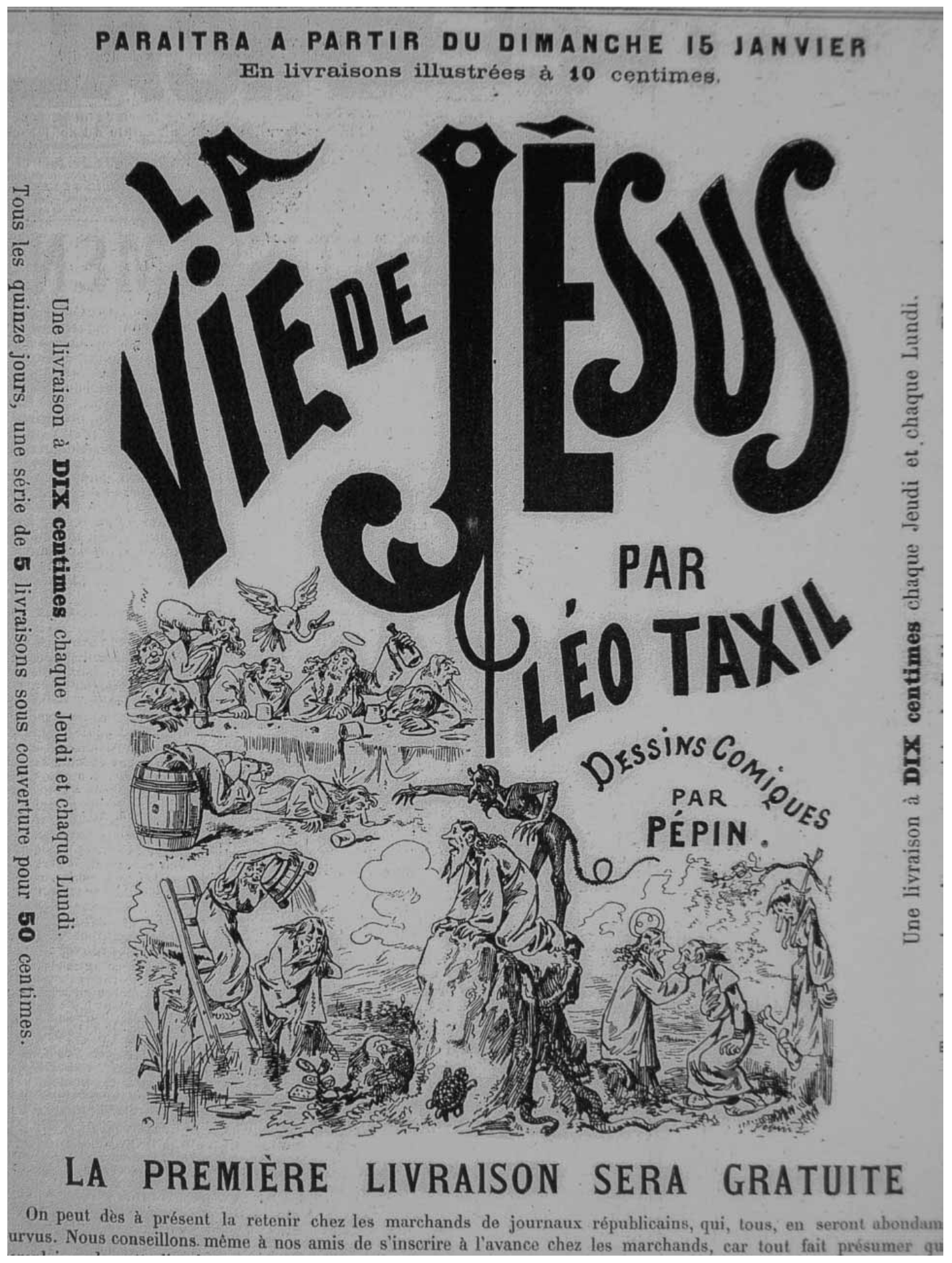

Fig. 7 
et un défenseur de la religion. Longtemps considéré comme une œuvre de Victor Hugo, il est illustré en 1881 par Alfred Le Petit.

Beausapin, auteur d'une Bible comique comme on l'a vu, projette lui aussi une Vie de Jésus en 1883, mais elle semble ne pas avoir paru ${ }^{23}$. Par contre, un peu plus tard, Gustave Frison rédige et illustre une Vie de Jésus racontée par un matelot ${ }^{24}$, qui connaît au moins deux éditions. L'auteur, sur un ton comique et très romancé, s'appuyant sur un langage oral et particulièrement argotique, décrit les apôtres comme une bande de parasites fainéants, portés sur la bouteille et séduits par leur «patron » (Jésus) pour l'efficacité de ses miracles. Le " charlatan ", répand parfois la bonne nouvelle, qualifiée "d'apoloches» (apologies) très confus qui jettent les apôtres, la population et le lecteur lui-même, dans la plus hilarante perplexité.

La parodie des dogmes, en plus des rééditions des ouvrages précités, s’invite dans une presse satirique républicaine ou anticléricale de plus en plus vigoureuse. Dans cette période où se multiplient les publications périodiques bibliographiques, le Trombinoscope propose un numéro sur Dieu illustré d'un dessin de Moloch ${ }^{25}$ en couleur [fig. 8]. La Calotte éditée dans la région de Marseille autour de 1900 , et qui vise à devenir un organe politique réunissant divers groupes libres penseurs, publie des dessins virulents et dégradants contre Dieu et Jésus. De son côté, le dessinateur Grandjouan, produit un violent numéro de L'Assiette au Beurre contre le Christ, intitulé "Ecce homo" et sous-titré "numéro antichrétien ». Il y présente un Jésus méchant et vulgaire, symbolisant le rôle néfaste du christianisme mais dans une veine quelque peu antisémite... De son côté, l'hebdomadaire franco-belge Les Corbeaux, qui invente en 1905 le militantisme par l'image en diffusant à un milieu activiste des affiches, des cartes postales, des tracts, des papillons gommés (ancêtres de l'autocollant) illustrés de caricatures ${ }^{26}$, publie régulièrement les épisodes d'une «Bible cocasse » et en 1907, une " Histoire authentique, posthume et sociale de la Sainte Famille par Monsieur JésusChrist, officier de la Légion d'Honneur, Chevalier du Mérite Agricole et Officier de l'Instruction Publique ".

La presse humoristique ou satiriste mais non exclusivement anticléricale comme Le Grelot, Le Rire ou le Courrier français, mais aussi La Baïonnette par exemple, pendant la guerre 1914-1918, peut, à l'occasion, donner libre cours à un dessinateur pour illustrer tel ou tel épisode de la Bible, ou mettre en scène Dieu ou Jésus dans leurs supposés rapports avec les hommes. Après la guerre, dans les années 1930, le militant libre penseur Lorulot publie une Bible comique

23. Cet ouvrage est pourtant annoncé par la Librairie du Monde Comique, dans la Bible comique de BEAUSAPIN.

24. Gustave Frison, La Vie de Jésus racontée par un matelot, Paris, s.d. (vers 1899).

25. Le Trombinoscope, $\mathrm{n}^{\circ} \mathbf{1 9}$, août 1881.

26. Guillaume DoIZY, "Une revue anticléricale : Les Corbeaux », Gavroche, n 140 , marsavril 2005, p. 8-13. 


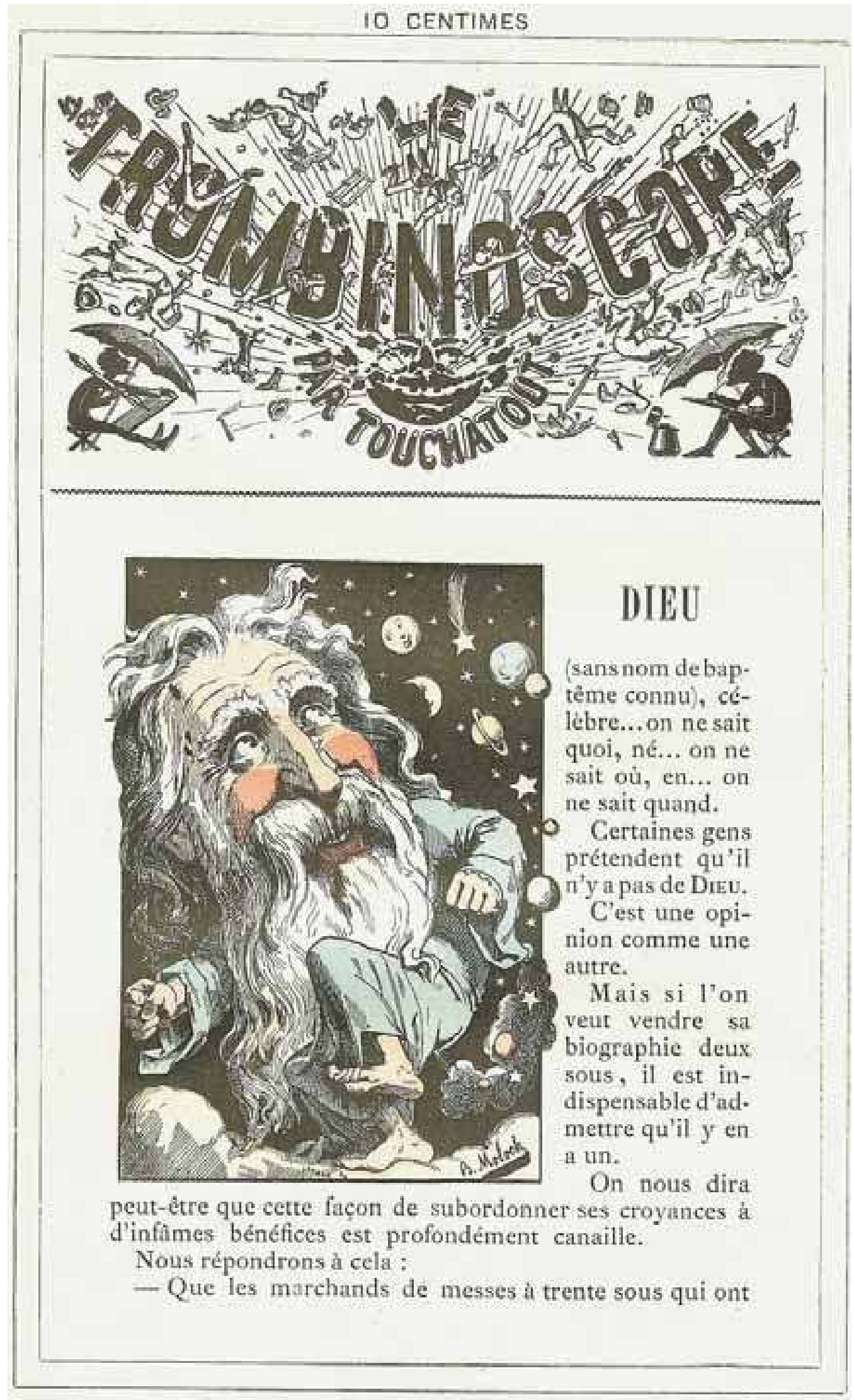

Fig. 8 
et une Vie de Jésus avec des dessins satiriques d'Armangeol. Citons aussi les dessins d'Effel à la fin des années 1950 réunis dans de petits fascicules illustrés reprenant les grandes phases de la création. Dans la décennie suivante, paraît Le livre des darons sacrés ${ }^{27}$, de Pierre Devaux, illustré par lui-même, et réédité quelques années plus tard avec la mention «la Bible en argot ${ }^{28}$.

\section{La Bible comique}

Tous les ouvrages illustrés visant les «saintes » Écritures depuis les années 1880 , font preuve de nuances sensibles. Les auteurs proposent soit des Bibles visuelles, c'est-à-dire composées de grandes illustrations légendées, soit de parodies textuelles où l'image, sous forme de vignettes de taille modeste, fonctionne comme un agrément comique secondaire. Parfois, le texte, très ancien, est réédité avec des illustrations récentes. Plusieurs décennies peuvent séparer l'un de l'autre. Deux attitudes prévalent chez les auteurs.

La première consiste à sélectionner des fragments de textes canoniques, pour les expliquer et les ridiculiser, souligner leur imbécillité avec des commentaires sérieux et comiques. Le jeu consiste alors à passer du texte au commentaire sans hiatus littéraire, en introduisant des réflexions qui paraissent d'autant plus acides, ironiques et drôles qu'elles sembleront être tirées des Écritures originelles. Pierre Malvezin, dans sa Bible farce, choisit d'indiquer les citations bibliques en caractère gras, pour mieux faire ressortir les incongruités du texte original. Léo Taxil, dans une édition de 1898, donne les "citations textuelles de l'écriture sainte " et les «réfutations opposées par Voltaire, Féret, Lord Borlingbroke, Toland et autres critiques". Lorulot, dans les années 1930 base sa critique des Écritures sur le même principe alternant commentaire et réflexion théologique. Dans son dialogue comique, Roussel de Mery suit globalement la logique événementielle des textes saints. Les deux orateurs, dans la discussion, usent parfois de citations, mais la forme du dialogue prévaut, les «preuves " et fragments de textes étant relégués à la fin. Car les auteurs les plus militants affirment des idées, ils ne se contentent pas de réjouir le lecteur. Il s'agit d'éduquer par le rire, de fournir les arguments les plus rationnels, d'offrir des armes à l'incroyant. Ces auteurs se veulent avant tout didactiques.

À l'opposé, les écrits les plus comiques paraphrasent les Écritures «sacrées » et produisent de véritables parodies. Il n'y a plus alors, en dehors de quelques apartés, de raisonnement sur telle ou telle parole de Dieu, telle ou telle contradiction du texte. Les protagonistes de l'Ancien et du Nouveau Testament voient

27. Pierre Deveaux, Le Livre des darons sacrés, Paris, Éditions de l'humour des temps, 1960.

28. Pierre Deveaux, Le Livre des darons sacrés ou la Bible en argot, Paris, Librairie G. Kogan, 1974. 
leur personnalité totalement transfigurée. Dieu baille, rit, pique de "saintes » colères, se fait méchant et cynique ou au contraire naiff et faible, etc. La Vie de Jésus de Frison ou de Taxil se transforment en de véritables romans rocambolesques et légers où prédominent les dialogues, alors que l'action prime sur la réflexion. La satire des Écritures puise dans les artifices de la littérature légère pour égayer le lecteur, le faire rire et l'émouvoir.

Pour désacraliser les personnages bibliques, les dessinateurs transposent leur parodie dans le temps présent. L'anachronisme fonctionne comme un effet comique : Caïn tue Abel à coup de fusil, Joseph utilise un vélo pour aller en Égypte avec sa petite famille; pour son ascension, Jésus pratique le ballon dirigeable, etc. Le décor se veut tout autant contemporain des auteurs. On peut alors parler de hiatus géographique. Différentes scènes de la Bible de Lavrate se situent à Bondy, dans la région parisienne. Jérémie, le "charlatan prophète " qui «pleura pendant toute la durée du siège de Jérusalem ${ }^{29}$ n'est autre que Jules Favre (qui signa l'armistice de 1871 avec Bismarck) versant d'immenses larmes dans un casque à pointes retourné [fig. 9]; Beausapin campe ses héros dans le Paris des années 1880 avec ses théâtres, ses maisons de plaisirs, ses artères haussmanniennes, ses voitures, etc. Lucifer y devient «Lucy-Ferry ». Les Dix commandements permettent à l'auteur de la Bible comique d'évoquer les tensions sociales : «Biens d'autrui ne convoiteras/Pour les avoir injustement. » l'auteur explique : "Avis aux socialistes, possibilistes, anarchistes et autres nihilistes. Voilà du coup tranchée la querelle qui divise le prolétariat et l'infâme capital... » ${ }^{30}$.

Les personnages saints sont malmenés par les dessinateurs qui puisent dans le trivial la force du dénigrement. L'écrivain libre penseur s'adresse à «Bon papa Dieu » ou « Papa Sabaoth». Le dessinateur, lui, recourt à l'arme de la nudité, bien sûr, et multiplie les allusions licencieuses visuelles, censées égayer le lecteur. Dieu est présenté nu, seulement drapé de sa longue barbe blanche. Il dort dans la paille comme dans un dessin des Corbeaux, bercé par un doux rêve ${ }^{31}$ [fig. 10]. Et puis le voilà qui s'étire, baille bruyamment après avoir dormi une éternité. Pourquoi se décide-t-il soudain à créer le monde? Pour Malvezin, c'est sa conscience qui le tance et le somme de se réveiller. D'autres imaginent un Dieu voulant rompre avec l'ennui produit par cette torpeur éternelle...

Son petit corps malingre et dénudé, contraste avec l'immensité de sa tâche et... l'image du puissant dieu Créateur que l'Église catholique diffuse depuis des siècles. La création des étoiles? Voilà le Seigneur monté sur un escabeau accrochant les étoiles avec un marteau et des clous. La création du monde ? Sous le stylet d'Alfred Le Petit, Dieu se fait bricoleur. Il assemble différentes pièces de

29. Le Monde plaisant, $\mathrm{n}^{\circ} 181,5$ novembre 1881.

30. BeAUSAPIN, op. cit., p. 278.

31. "La Bible cocasse ", dessin d'Ashavérus, Les Corbeaux, 15 avril 1906. 


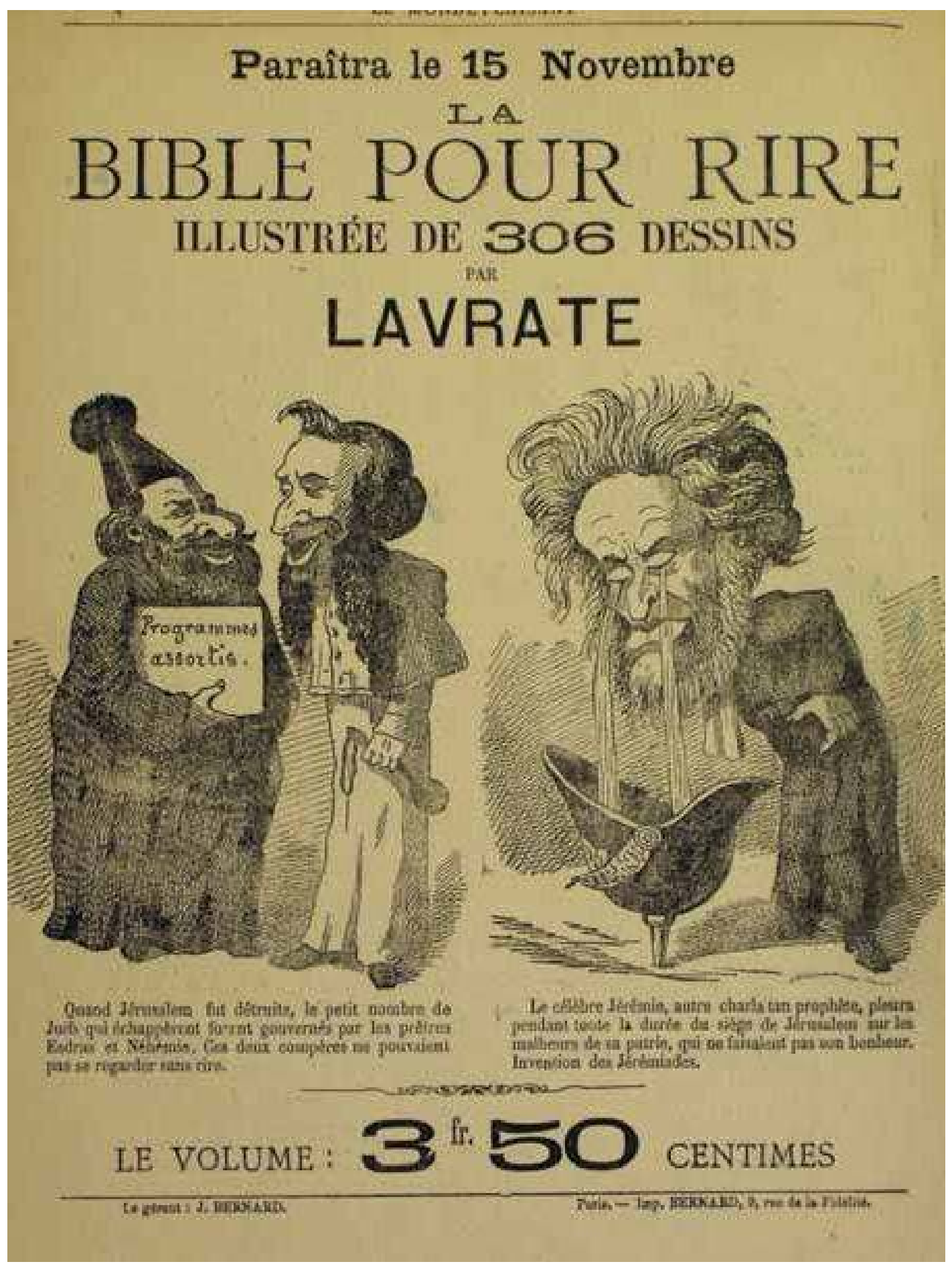

Fig. 9 


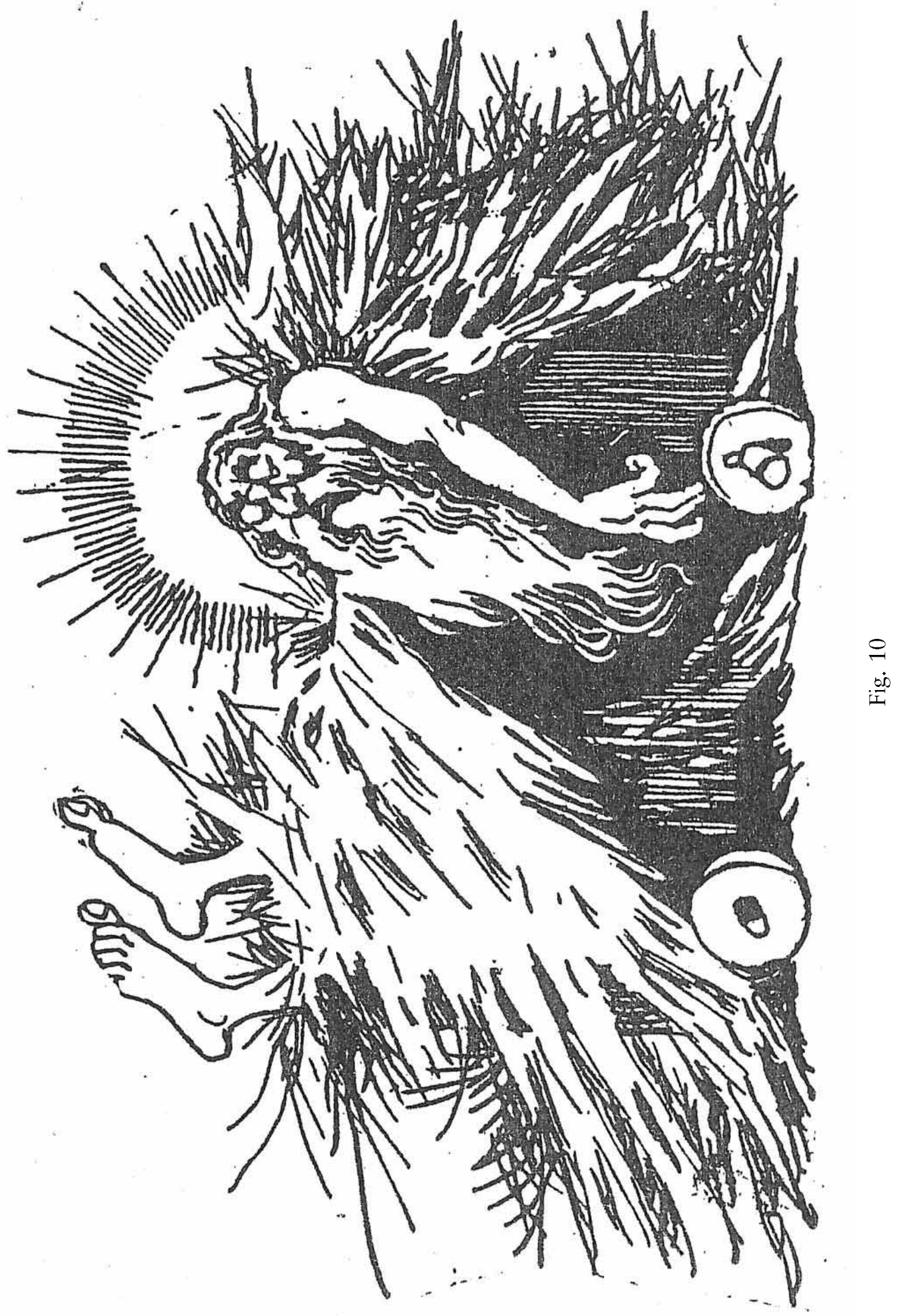


bois pour en faire des arbres fort peu réalistes. Doit-il s'adresser aux hommes? Le voilà descendant du ciel en voiture ou suspendu à l'envers sur un trapèze de cirque. Avec le mouvement, ses jupes se relèvent et on voit alors ses porte chaussettes... Si Dieu est représenté le plus souvent maigre, on peut aussi le voir sous l'apparence d'un homme fort charpenté, les pieds démesurément longs et les muscles saillants d'un athlète. Pilotell, le dessinateur communard dresse indirectement son portrait : sous l'image rebutante d'un vieux curé au nez déformé par l'alcool et envahi de verrues cette légende : «créé à l'image de Dieu »!

Quant à la «création » d'Adam et Ève et la question du péché, elle suscite l'imagination des caricaturistes. Ashavérus, dans Les Corbeaux, imagine un Dieu chirurgien muni d'une immense scie et qui extraie une côte sanguinolente du flanc d'Adam. L'arbre de la connaissance ? L'image se limite parfois à représenter un pommier. Dans Gros-Jean et son curé, Alfred Le Petit s'ingénie à transformer les feuilles d'arbre en mets les plus raffinés (rôtis, bouteilles de vin ou liqueurs, desserts, etc.) qu'interdit l'Église lors du Carême notamment. Le serpent tentateur, dans certains dessins, est présenté sous l'apparence d'un juge de la Troisième république, ou d'un Jésuite. Quant au péché, le plus simple, pour le suggérer, est de montrer, comme le fait le dessinateur Frid'Rick, Adam au bord d'un étang, une canne à pêche à la main... Mais bientôt le couple est chassé du paradis par un garde napoléonien sabre au clair! L'image satirique s'amuse de tout. Pour son Arche, Noé obtient les plans détaillés de la main d'un ange. Mais il est bien difficile de faire entrer tous les animaux dans une si petite embarcation. Noé tente de faire rentrer une immense baleine... dans un petit bocal en verre. Et quand la mer se retire, voilà l'arche coincée en équilibre sur la pointe du mont Ararat!

Le Nouveau Testament n'est pas mieux traité. La «fécondation » de Marie par l'Esprit "saint " fait beaucoup rire les dessinateurs qui imaginent un ange doté de charmes sans limites descendre du ciel pour conquérir la belle, et se faire réprimander à son retour au Paradis, parce qu’il rentre " très tard ». La caricature représente l'amant de Marie sous l'apparence du soldat Panthéra qui, pour faire « avaler » la chose à Joseph, se munit d'une bonne paire d'ailes en bois et singe une apparition nocturne en se faisant passer pour un messager de Dieu, justifiant la grossesse miraculeuse de la "Vierge ". Il pousse alors à Joseph de proéminentes cornes de cocu, si grandes qu'en couverture des Corbeaux, Marie et l'enfant peuvent même y faire de la balançoire...

Jésus et les apôtres semblent sales, leurs visages ne respirent pas l'harmonie, les voilà transformés en " apaches » sortis tout droit des bas-fonds du tout début $\mathrm{du} \mathrm{XX}^{\mathrm{e}}$ siècle. Ils sont présentés comme une bande de miséreux calculateurs, jurant à l'occasion, buvant à profusion, paresseux et délurés. On les voit souvent vautrés ; on ne compte plus les dents cassées à leurs sourires béats. La caricature s’ingénie à «trahir » ${ }^{32}$ les corps, comme on le constate. Nudité, postures

32. Bertrand TILlıer, La Républicature, Paris, CNRS Éditions, 2001, p. 110. 
dégradantes (Dieu semble parfois déféquer...), saleté, bouches édentées, visages traversés de spasmes évocateurs de désordres moraux, etc. Certes, les dessinateurs usent de moyens visuels plus mesurés que dans leurs attaques contre le clergé. Certaines images sont néanmoins fort irrespectueuses, comme cette nativité où Marie est animalisée en vache, Jésus en petit cochon langé et les rois mages en coq, en oie et en canard.

Contre les Écritures «saintes », la moindre saillie comique semble profondément impie et blasphématoire. L'objectif général, est de contrecarrer le caractère sacré que l'Église a progressivement attribué aux protagonistes des Écritures. Le dessin anti-religieux les présente sous un jour profondément humain, où cette humanité apparaît comme particulièrement faible et vile. Le lecteur peut alors à loisir éprouver un sentiment de supériorité face à ces êtres dérisoires.

Il faut comparer ces représentations à celles que l'Église a construites à partir du second Concile de Nicée pour "façonne[r], au fil des siècles, l'esprit de ceux qui n'ont aucun accès à la culture savante " ${ }^{33}$, et que le dessinateur se fait fort de parodier, détourner, ridiculiser, transformer. Mais surtout, il en reprend les codes, afin d'être compris par ses lecteurs. Dieu ne peut être que barbu et vieux, même si l'anticlérical le montre nu et maigre, assis sur les fesses ou avec des oreilles d'âne. Jésus, lui, sera jeune et plutôt mince, habillé pauvrement, quoique devenu rigolard ou hystérique, gesticulant dans tous les sens. Le dessinateur libre penseur n'invente pas un langage nouveau pour signifier le divin : il reprend la division de l'espace divin/terrestre matérialisé par une auréole de nuages, véritable frontière entre le monde de Dieu et celui des hommes. Il réemploie les stigmates élaborés par l'imagerie chrétienne pour caractériser la sainteté : auréoles plus ou moins exagérées ou transformées, série de traits rayonnants (rayons solaires), qui confèrent un caractère sacré à des personnages (ou des animaux) qui n'en ont vraiment pas l'allure. Le contraste provoque alors le rire.

Écrivains et dessinateurs anticléricaux recourent à la parodie et s'ingénient à singer certaines scènes de l'Ancien et du Nouveau Testament, qui sont de véritables icônes, vu la fréquence de leurs représentations dans l'imagerie religieuse. La "sainte famille " dans l'étable reprend la composition en triangle de la peinture en la modifiant à peine. Il suffit alors au dessinateur de rajouter une auréole sur la tête de la vache, de montrer les fesses du petit jésus souillées par le fruit de sa digestion, etc., pour verser dans le blasphème. Certaines images singent le style graphique du Moyen Âge, comme dans cette Ascension d'Alfred Le Petit parue dans Gros-Jean et son curé, où Jésus monte au ciel en ballon dirigeable [fig. 11]. Dans la scène, les personnages en prière sont affublés de vêtements aux plis géométriques caractéristiques des peintures de la fin du Moyen Âge. D'autres caricatures utilisent un épais cerne noir visant à reproduire le style des vitraux

33. Jacques Paul, Histoire intellectuelle de l'Occident médiéval, Paris, Armand Colin, 1998, p. 12. 
DE LA CARICATURE ANTICLÉRICALE À LA FARCE BIBLIQUE - 83

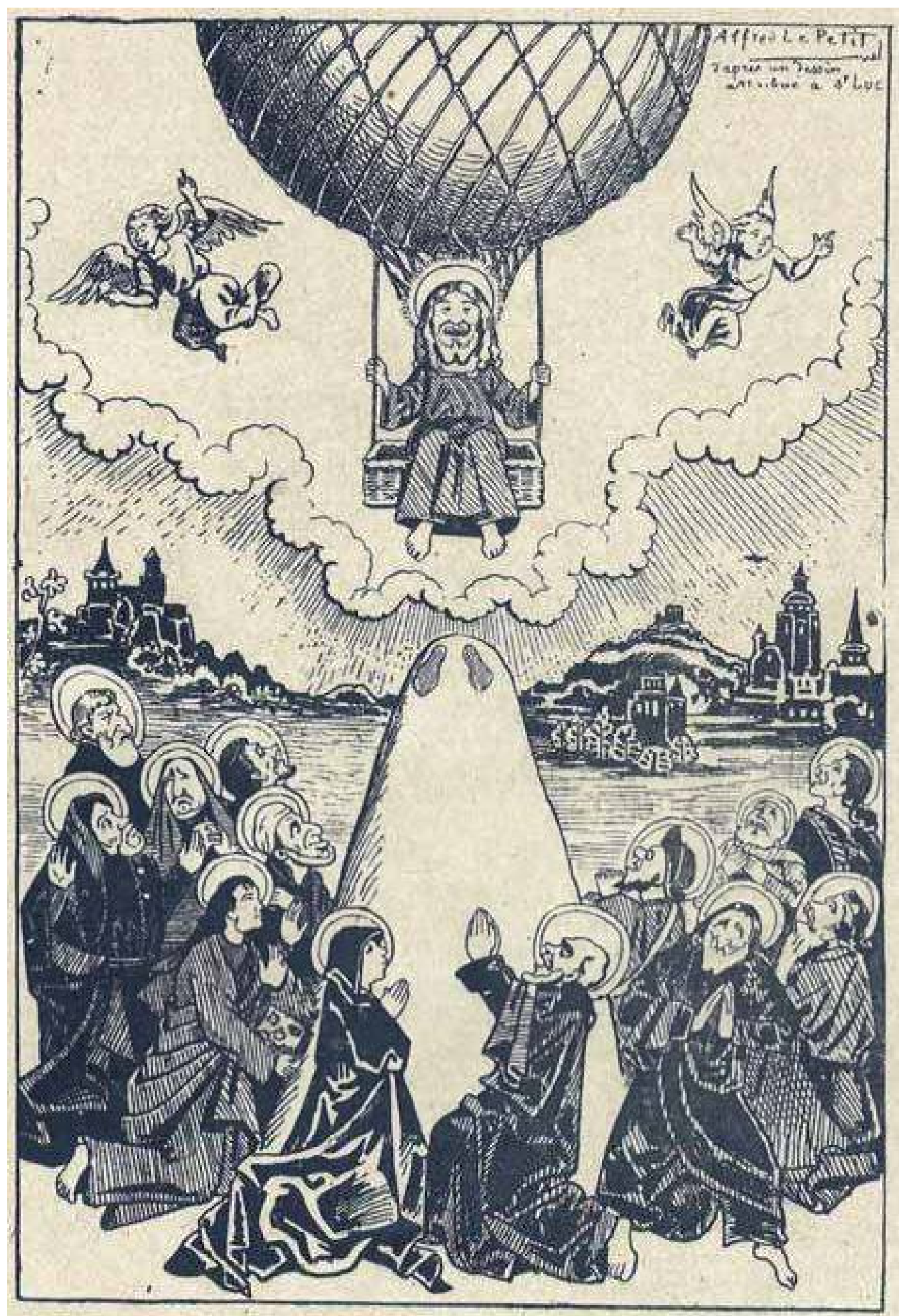

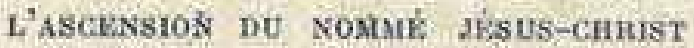

Fig. 11 
médiévaux et inscrivent leur dessin dans un cadre qui n'est plus rectangulaire, mais s'apparente à une baie d'église ou de cathédrale, dont le sommet se termine en arc brisé.

\section{L'Église ne rit pas}

Les anticléricaux n'ont pas retourné le rire contre les dogmes par hasard. En effet, comme l'écrit par exemple Baudelaire qui s'interroge sur l'essence du rire dans les années 1850, "les livres sacrés, à quelques nations qu'ils appartiennent, ne rient jamais ${ }^{34}$. La question du rire de Jésus a fait discuter les théologiens, certains considérant même que non seulement il n'avait jamais ri, mais qu'en plus, sa condamnation du comique était sans appel et même dogmatique. Pourtant, dans l'Ancien Testament, il arrive à Dieu de rire à plusieurs occasions. Mais il s'agit d'un rire vengeur. Dieu rit contre les impies, et son rire a la puissance de la foudre destructrice. Et si Dieu s'arroge parfois le droit de s'esclaffer méchamment, il n'en va pas de même pour l'homme. Alors qu'Abraham et sa femme Sarah, après une vie de stérilité, rient quand Dieu leur annonce la naissance d'Isaac, Jahvé s'énerve contre l'impertinence de ses créatures : douteraient-ils de la puissance céleste? Le rire apparaît bien alors comme irrespectueux envers la divinité, et doit être banni.

Dans la Bible, le livre de l'Ecclésiaste fait parler le «sage». Pour lui, « la douleur est préférable au rire », car « elle attriste le visage, mais elle rend le cœur meilleur. On rencontre le sage là ou les hommes souffrent et le sot là où ils s'amusent ${ }^{35}$. L’Église catholique a condamné les plaisirs et le rire, imposant au fil des siècles une morale austère pour le croyant et le bas clergé, mais plus «libérale» pour les élites religieuses. Elle voit le diable derrière le rire. Dans l'iconographie du Moyen Âge et de la Renaissance c'est le diable, que l'on représente le rire aux lèvres, pas Dieu, et encore moins Jésus. Voilà pourquoi certains anticléricaux, comme Léo Taxil par exemple, choisissent pour mot d'ordre «tuons-les par le rire » en visant les cléricaux. Il s'agit de prendre le contre-pied de la rigidité religieuse. Le rire, quelles que soient ses visées, apparaît comme une attitude sulfureuse, un acte de rébellion opposé au sérieux de la prière, à la raideur de la foi. Le rire rentre finalement dans le champ politique comme une arme de combat, et notamment pendant la Révolution française où s'impose une véritable «guerre du rire ${ }^{36}$. À la fin de l'Empire, l'esprit satirique d'un Rochefort avec sa Lanterne relève encore de ce rôle éminemment contestataire de l'éclat de rire. Contre la religion, le rieur affiche une ironique liberté à propos de la vie

34. Charles BaUdelaIRE, Curiosités esthétiques. L'art romantique, Paris, Édition de H. Lemaitre, Garnier, 1962 , p. 251.

35. L'Ecclésiaste (VII, 6-7).

36. Antoine DE BAECQUE, Les Éclats du rire, la culture des rieurs, XVIII siècle, Paris, Calman-Levy, 2000, p. 10. 
et ne semble plus victime de la peur de la mort ou du Jugement. Rire éloigne de Dieu en détournant l'homme de la méditation mystique; le rire apparaît finalement comme l'apanage du philosophe, du libertin, de l'être émancipé, du libre penseur. Le rire, par essence irrespectueux, se fait l'ami de la raison par la prise de distance qu'il permet. Il devient diabolique et sacrilège, surtout quand il s'en prend à Dieu.

On peut se demander quel sens donner à cette expression comique ou violemment agressive dirigée contre les dogmes. Tourner en dérision les Écritures revient-il seulement à provoquer le rire comme à propos de tout autre sujet, toute autre cible? On pourrait le croire, au regard des dessins de Lavrate par exemple, qui utilise sa verve naïve aussi bien contre les curés, Dieu, les pompiers ou la gent paysanne. Le sacré semble presque devenu une cible comme les autres sous la plume des satiristes en ces débuts de III $^{\text {e }}$ République où l'on goûte avec délice la puissance de la dérision. Cette appréciation semble anachronique, et reflète davantage un relativisme moderne, qu'une réalité plus ancienne. À l'époque de la chute de Napoléon III et de l'installation de la République, l'Église et l'État sont intimement liés par le Concordat, les fêtes religieuses accompagnent et justifient le calendrier politique. La société officielle dans son ensemble s'agenouille devant Dieu. Le catholicisme se raidit. Fin 1870, le Vatican décrète l'infaillibilité papale, et l'Église multiplie les pèlerinages qui obtiennent alors un succès populaire certain $^{37}$.

Pendant la première décennie de la III ${ }^{e}$ République le poids de l'Église grandit encore. Suite à la peur qu'a suscitée la Commune de Paris, on élève le SacréCœur sur la butte Montmartre à partir de 1876 pour fêter le retour à l'ordre ; le monarchiste Mac-Mahon impose une poigne de fer sur les consciences et le droit d'expression. La loi condamne encore toute atteinte à la morale religieuse, reprenant les termes de l'attirail répressif imposé par Napoléon III. Dans ce contexte, l'anticléricalisme apparaît comme profondément subversif. Il forme une contre-attaque à l'offensive cléricale et réactionnaire. Les tribunaux ne s'y trompent pas: Malvezin écope de trois mois de prison pour avoir, comme il l'explique lui-même, "critiqué et flétri les absurdités et les immoralités de la vraie Bible ${ }^{38}$ dans sa Bible farce au milieu des années 1870. La cour Suprême, puis la cour de Cassation confirment la condamnation. L'avocat Abel Faivre, pour sa défense, compare le texte incriminé à certains passages des Écritures qui sont plus immoraux encore. Mais rien n'y fait. Un opuscule édité en 1799, La Guerre des Dieux d'Evariste Parny, provoque les foudres de la justice. Des dizaines de condamnations pleuvent sur les libraires et les colporteurs qui en assurent la diffusion entre 1825 et 1865 . Au menu, prison et amendes pour tout le monde. Il ne s'agit là que de quelques exemples. Après le vote de la loi de

37. Claude Coulot, René HeYer, dirs, De la Bible à l'image, Strasbourg, Presses Universitaires de Strasbourg, 2000.

38. Pierre MaLVEZIN, Bible farce ou Bible comme elle est, 1881, prospectus. 
1881 instaurant la liberté de la presse, la justice peine à sanctionner les images impies. Il lui reste « seulement » le délit d'outrage aux bonnes mœurs, la critique de la religion n'étant plus considérée interdite. Entre autres rares condamnations, celle de la revue La Calotte diffusée dans la région de Marseille et au Havre, saisie pour avoir osé représenter la "Vierge " enceinte ${ }^{39}$.

Les tenants du judaisme, puis du catholicisme, dénoncent toute atteinte à l'image de Dieu qu'ils appellent blasphème. Ils appuient leur défense sur les Écritures elles-mêmes, et ceux qui, tout au long de l'histoire, ont empêché toute forme de remise en cause des dogmes. La Bible ne contient-elle pas ces paroles terribles, véritable appel au meurtre : «Celui qui blasphémera le nom de l'Éternel sera puni de mort, toute l'assemblée le lapidera. Qu'il soit étranger ou indigène, il mourra, pour avoir blasphémé le nom de Dieu ${ }^{40}$. Ce qu’Alfred Le Petit traduit par un jet de pierre ${ }^{41}$ de la main de Dieu lui-même [fig. 12].

Les pères de l'Église Jérôme, Grégoire de Naziance ou Augustin, vont très loin dans leur condamnation du blasphème : pour eux, le blasphémateur est pire que les meurtriers du Christ. Pour d'autres, celui qui professe des injures contre le divin s'apparente au déicide. Pour l'Église, il n'est rien de pire que la souillure consciente de la divinité, alors que l'homme devrait remercier Dieu quotidiennement pour les bienfaits qu'il lui prodigue.

\section{S'affranchir du " sacré "}

Le rire antireligieux des années 1880, mu par un mouvement anticlérical et libre penseur populaire sans précédent, agresse violemment le christianisme, - habitué jusque-là à voir seulement attaqués ses ministres - au nom d'ailleurs de la «vraie » religion, qui serait humaine et humble, au service des pauvres et des faibles. La puissance de l'imagerie sur Dieu et les dogmes, doit s'évaluer à l'aune de la puissance présumée du Créateur en cette fin de XIX siècle. Il nous faut faire un profond effort d'imagination pour concevoir l'inconcevable, c'està-dire l'immense respect social pour la chose sacrée et l'imprégnation très forte des esprits qui en résultait. Le sacré tient alors une telle place dans la société que la moindre mise en cause du clergé, semble encore considérée comme un affront à Dieu ${ }^{42}$.

L'anticléricalisme qui pousse jusqu'à l'antireligion, même en se limitant au domaine comique n'est pas un jeu. Il permet au sceptique, à l'indifférent voire à l'athée, d'affaiblir la puissance des représentations que la société a glissé dans

39. La Calotte de Marseille, 8 janvier 1899.

40. Lévitique, 24.10-16.

41. Pierre Malvezin, op. cit.

42. Alain Cabantous, Histoire du blasphème en Occident XVI'-XIX ${ }^{e}$ siècles, Paris, Albin Michel, 1998, p. 191. 


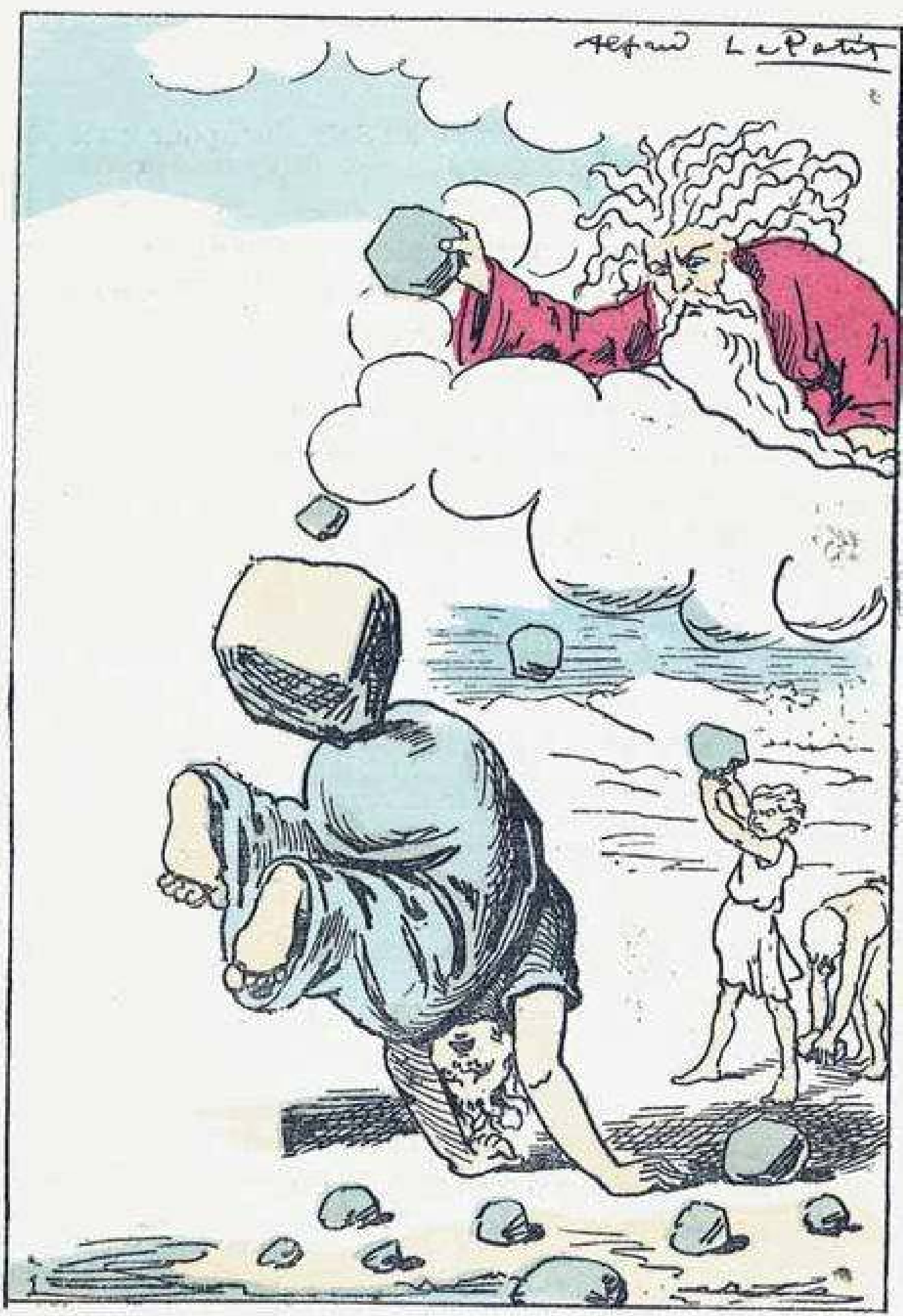

Il arriva ensuite qu'un homme blasphéma. Et le Seigneur, consulté par Moïse, dit: "Que cet homme soit lapidé, " Et le coupable fut lapidé... 
les esprits, de doubler la culture religieuse qui imprègne l'homme du XIXe siècle, d'une contre culture a-religieuse. La figure du Dieu tout puissant des images pieuses, cette figure qui impose le respect voire effraie le croyant, s'associe dorénavant à celle de ce petit bonhomme cocasse et nu à la barbe démesurée, véritable marionnette drolatique.

Personne ne peut croire que ces caricatures peuvent, à elles seules, détruire la croyance, annuler la foi, inspirer le doute. L'indifférent ne croit plus au dogme mais il doit encore s'affranchir du respect social à l'égard du sacré qui l'imprègne encore. Il doit s'affranchir du conformisme social qui étend ses tentacules très largement au-delà du cercle limité du clergé et des dévots. Il faut rappeler que la charge antireligieuse doit combattre un gros millénaire d'imagerie chrétienne. L’Église a, en effet, largement utilisé l'image dans sa "propagande ${ }^{43}$ des Écritures depuis le Moyen Âge jusqu'à nos jours. On ne compte pas les représentations de scènes bibliques dans les églises, les musées, les images d’Épinal édifiantes, les catéchismes ou les Bibles illustrées qui ont progressivement modelé les esprits.

La satire contre Dieu a profité de l'engouement extraordinaire pour l'image satirique à la fin du XIX ${ }^{\mathrm{e}}$ siècle, véritable " siècle de l'image ${ }^{44}$ comme le rappelle l'historien Laurent Gervereau. Si la caricature offre une prise de distance permise par la dérision, le dessin anticlérical permet, lui, une transgression plus profonde. Par sa puissance d'expression, l'image satirique impie donne un sentiment de réalité, d'extériorité au blasphème. Face à l'image, le sceptique n'est plus seul. Il n'est plus seul à se gausser des "âneries " de la Bible. L'image satirique, en effet, fonctionne comme un compagnon familier avec lequel s'instaure un dialogue sulfureux et complice. L'image imprimée, par son existence même (dans un livre, sur une carte postale ou une affiche, c'est-à-dire dans l'espace public), renforce l'incroyant, l'autorise à re-penser Dieu.

Ces images, et ce fut là leur rôle, auront largement participé à la désacralisation du sacré. Elles ont pu s'imposer à la fin du XIXe siècle grâce à l'affirmation des idées républicaines et libres penseuses, grâce au fait que tout un milieu social se mit à lutter contre l'obscurantisme de l'Église catholique. Notons que le rire antireligieux fut avant tout "populaire ». Les élites, en dehors du mouvement ouvrier révolutionnaire, même les plus avancées sur la question de la laïcité, restent, tout au long du XIX siècle, profondément déistes ou spiritualistes. Elles répugnent à se moquer ouvertement des Écritures, et préfèrent la critique sérieuse aux « excès » de la caricature.

Le blasphème visuel, auquel nous convient ces caricatures de Dieu, sous forme de bibles satiriques ou de dessins isolés, semble plus libérateur que l'insulte verbale à l'encontre de la divinité. Car la caricature n'est pas un élément éphémère

43. Jacques PaUL, op. cit., p. 12.

44. Laurent GervereaU, Les Images qui mentent, Histoire du visuel au XXe siècle, Paris, Seuil, 2000, p. 38. 


\section{WER HAT ANGST}

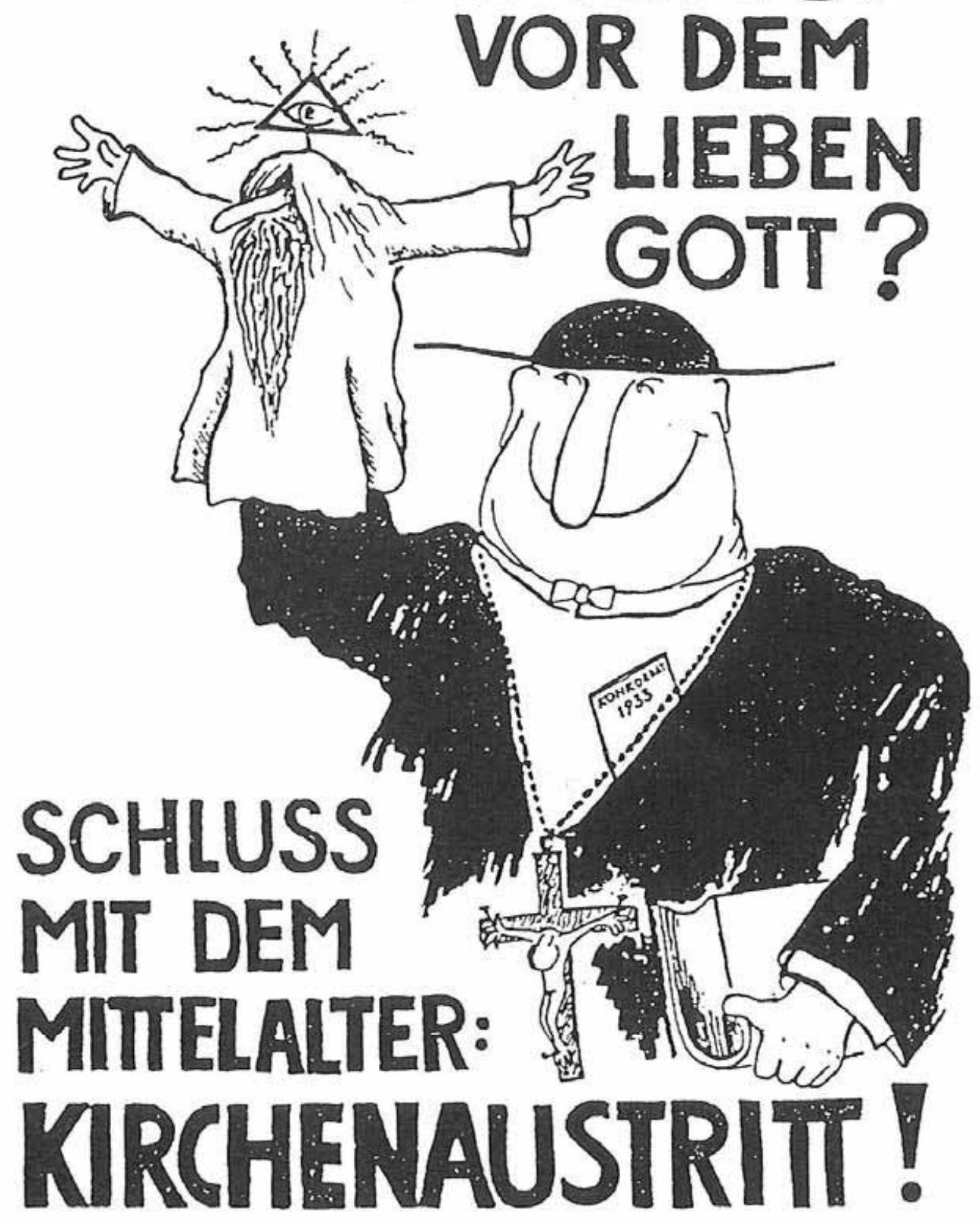

MR Marxistisch-Reichistische Initiative

Fig. 13 
et immatériel. Elle existe bel et bien, comme un fragment de la "Création ", et ce, malgré la condamnation sociale qui l'accable. Malgré la supposée puissance divine capable de submerger le monde par un déluge apocalyptique ou de foudroyer des villes entières, les Églises doivent organiser elles-mêmes la riposte contre l'impiété (Inquisition, recours à la justice, etc.). Le blasphème visuel rend éclatant la faiblesse du divin ${ }^{45}$ [fig. 13], incapable de se défendre lui-même. Par sa diffusion, par son existence même, par son arrogance ${ }^{46}$ à ne pas craindre la puissance divine, l'image satirique contre le dogme détruit le reste de crainte mêlée de respect qui sourd encore au fond des «cœurs ». Elle aide à libérer les consciences d'un puissant tabou. Dans un univers empreint de religion, elle vise à prouver finalement que Dieu n'existe pas.

Guillaume DOIZY

Centre de recherches en arts - Université de Picardie Jules Vernes

\section{Résumé}

La caricature anticléricale vise, depuis son origine, le clergé sous l'angle de sa moralité, de ses prises de positions politiques et de son rôle considéré comme oppressif dans la société. À la fin du XIX siècle, la caricature devient antireligieuse. Elle attaque dorénavant les dogmes. L'Ancien et le Nouveau Testament sont largement parodiés et illustrés de caricatures. Ce mûrissement de la caricature contre la religion s'appuie en fait sur des siècles de critique rationaliste ou satirique de la Bible. On s'interrogera sur la rhétorique propre de ces images et le rôle social dévolu au blasphème, considéré par les dessinateurs libres penseurs comme une arme corrosive destinée à renforcer le sentiment antireligieux. Car il s'agit bien de propagande où les stéréotypes véhiculés par la caricature visent à déconstruire l'image édifiante des dogmes diffusée par l'Église. Dans cette perspective, le dessin anticlérical détourne les codes mêmes des représentations religieuses, sur lesquels la religion chrétienne appuie sa diffusion depuis le Moyen Âge.

Mots-clés : caricature anticléricale, Bible comique, politique anti-religieuse, blasphème, XIX ${ }^{\mathrm{e}}$ siècle.

45. Un siècle plus tard, la caricature antireligieuse se moque avec la même arrogance blasphématoire de la supposée puissance de Dieu (Dessin tiré de Ketzerbriefe, $\mathrm{n}^{\circ} 10$, AhrimanVerlag, avril 1988, Allemagne).

46. Dans Le Monde Plaisant du 11 octobre 1884, un rédacteur conclut ainsi une historiette visant des curés portés sur la bouteille et les femmes: "Si l[']auteur de tout ce scandale, ne rôtit pas éternellement, c'est qu'il faudra désespérer de la justice divine ». Un exemple parmi bien d'autres. 


\section{Abstract}

Since its origin, the anticlerical caricature criticizes the clergy under the angle of its morality. It also criticizes its political statements and its role, considered as oppressive in society. At the end of the XIX ${ }^{\text {th }}$ century, the caricature becomes antireligious. From now, it attacks on the dogmae. The Ancient and the New Testament are widely parodied and illustrated with caricatures. This maturing of the caricature against the religion is in fact based on centuries of rationalist or satiric criticism of the Bible. We shall wonder about the proper rhetoric of these images and the social role devoted to blasphemy, considered by the free thinker draftsmen as a corrosive weapon intended to strengthen the antireligious feeling. Because it is indeed a question of propaganda, where stereotypes conveyed by the caricature aim at deconstructing the edifying image of the dogmae spread by the Church. In this perspective, the anticlerical drawings divert the codes of religious representations, on which the Christian religion relies for its diffusion since the Middle Age.

Key words: anticlerical caricature, Bible-joke, blasphemy, anti-religious politics, $\mathrm{XIX}^{\text {th }}$ Century

\section{Resumen}

El objeto de la caricatura anticlerical es, desde su origen, el clero desde el punto de vista de su moralidad, de sus posturas politicas y de su papel considerado como opresivo en la sociedad. Al final del siglo XIX la caricatura se vuelve antireligiosa. Ataca a partir de ese momento los dogmas. El Antiguo y el Nuevo Testamento son ampliamente parodiados e ilustrados de caricaturas. Esta maduracion de la caricatura contra la religion se apoya de becho en siglos de critica racionalista o satirica de la Biblia. Se examinara la retorica propia de estas imagenes y el papel social atribuido a la blasfemia, considerada por los dibujantes librepensadores como un arma corrosiva destinada a reforzar el sentimiento antireligioso. Pues se trata en efecto de propaganda en la que los estereotipos transmitidos por la caricatura intentan contradecif la imagen edificante de los dogmas difundida por la Iglesia. En esta perspectiva, el dibujo anticlerical desvia los codigos mismos de las representaciones religiosas, sobre los cuales la religion cristiana basa su difusion desde la Edad Media.

Palabra clave : caricatura anticlerical y antireligiosa, Biblia, blasfemia, siglo XIX. 
